\title{
MAPEAMENTO GEOMORFOLÓGICO DO SÍTIO URBANO DE JATAIZINHO, BAIXO CURSO DO RIO TIBAGI -PR
}

\author{
Rodrigo Vitor Barbosa Sousa \\ Centro Estadual de Educação Tecnológica Paula Souza - CEETEPS \\ rorvbs@gmail.com
}

Paulo Cesar Rocha

Universidade Estadual Paulista - UNESP -, Campus de Presidente Prudente, Departamento de Geografia pcrocha@fct.unesp.br

Isabel Cristina Moroz-Caccia Gouveia Universidade Estadual Paulista - UNESP -, Campus de Presidente Prudente, Departamento de Geografia icmoroz@gmail.com $\begin{array}{r}\text { Julio Kiyoshi Hasegawa } \\ \text { Universidade Estadual Paulista - UNESP -, Campus de Presidente Prudente, Departamento de Cartografia } \\ \text { hasegawa@fct.unesp.br }\end{array}$

\begin{abstract}
RESUMO
As formas de relevo do sítio urbano de Jataizinho, baixo curso do Rio Tibagi - PR, foram mapeadas com o objetivo de auxiliar o entendimento das causas responsáveis pelas inundações nesta cidade. O mapeamento geomorfológico foi realizado por meio de estereoscopia digital, de modo que o modelo estereoscópico foi construído com base em aerofotos da década de 1970, com escala de 1:25000, as quais foram georreferenciadas através de coordenadas geodésicas obtidas por meio de técnicas GNSS. As formas de relevo mapeadas foram colina - Dc, terraço - Atf e planície fluvial - Apf. O nível de margens plenas do Rio Tibagi foi calculado em $339,346 \mathrm{~m}$ e a cota zero do primeiro lance de régua da estação fluviométrica de Jataizinho - 64507000 - foi calculada em $334,020 \mathrm{~m}$. Através da sobreposição de imagens orbitais, verificou-se que atualmente muitas planícies fluviais - Apf -, são ocupadas pelos moradores da cidade de Jataizinho. Os resultados obtidos mostraram-se satisfatórios, de modo que o mapeamento geomorfológico poderá ser utilizado como ferramenta de apoio ao planejamento territorial e ambiental da cidade de Jataizinho.
\end{abstract}

Palavras-Chave: Geomorfologia. Geotecnologia, Inundação.

\section{GEOMORPHOLOGYCAL MAPPING OF THE CITY OF JATAIZINHO, LOW COURSE OF THE TIBAGI RIVER, PARANÁ STATE, BRAZIL}

\begin{abstract}
Relief forms of the city of Jataizinho, located in the low course of the Tibagi River, Paraná State, Brazil, were mapped with the objective of helping the understanding of the responsible causes of flood in this city. The geomorphologycal mapping was realized through digital stereoscopy. The stereoscopycal model was based in Jataizinho aerial photographs of 1970's with 1:25000 scale, georeferenced with geodesic coordinates obtained through GNSS techniques. The mapped relief forms were hill - Dc, terrace - Atf and floodplain - Apf. The bankfull stage of the Tibagi River was calculated in $339.346 \mathrm{~m}$ and the Jataizinho fluviometric station zero level was calculated in $334.02 \mathrm{~m}$. Through orbital images overlap was observed that many floodplains - Apf - , are occupied by Jataizinho city residents currently. The obtained results were satisfactory so that the geomorphologycal mapping will can be utilized as base to the territorial and environmental planning of the city of Jataizinho.
\end{abstract}

Keywords: Geomorphology. Geotechnology. Flood.

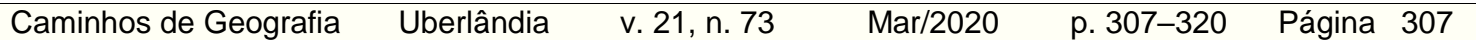




\section{INTRODUÇÃO}

Não é raro encontrar na literatura geográfica brasileira e de áreas correlatas, trabalhos que tratem de problemas relacionados ao fenômeno de inundação. A obra de Brasil (2005), por exemplo, apresenta as principais causas que potencializaram a ocorrência de inundação, em diferentes cidades do país, a saber, Manaus, Recife e Santo André, e os esforços que órgãos municipais, estaduais e federais têm realizado, a fim de minimizar os impactos socioeconômicos nestes locais.

O mapeamento realizado por Brasil (2015a; 2015b), aponta que a cidade de Jataizinho apresenta alta vulnerabilidade a inundações. Destaca-se que, são focados os eventos de inundações graduais ou de planície, os quais possuem, como característica principal, a subida e a descida paulatina da cota fluviométrica dos rios.

De acordo com França (2002, p.55), a cidade de Jataizinho é uma das mais afetadas pelas inundações do Rio Tibagi. Nesse sentido, o objetivo da presente pesquisa foi realizar um mapeamento geomorfológico do sítio urbano de Jataizinho, a fim de auxiliar o entendimento das causas responsáveis pelas inundações nesta cidade; ressaltando que o cerne da pesquisa não foi avaliar riscos ou vulnerabilidades a inundações.

\section{BREVES CONSIDERAÇÕES TEÓRICAS}

Sendo a inundação uma condição existente quando a vazão de um rio não pode ser canalizada dentro de seu canal normal, Christofoletti $(1980$, p.83) faz uma distinção entre os tipos de leitos fluviais, que correspondem aos espaços a serem ocupados pelo escoamento das águas. Assim, quanto ao perfil transversal nas planícies de inundação, podem-se distinguir os seguintes tipos de leitos fluviais: a) leito de vazante, b) leito menor, c) leito maior periódico ou sazonal, d) leito maior excepcional. Todavia, na prática essas delimitações são difíceis de serem traçadas, havendo nitidez maior entre o leito menor e o leito maior.

Com relação à deposição da carga detrítica carregada pelos rios, tal processo ocorre quando há diminuição da competência ou da capacidade fluvial. Essa diminuição pode ser causada pela redução da declividade ou pelo aumento da carga detrítica. A competência de um rio é entendida como o detrito de maior diâmetro transportado como carga de leito. Tal processo depende primariamente da velocidade, embora o tipo do canal, o tipo de sedimento e a temperatura da água também possam afetá-lo. Já a capacidade de um rio, refere-se à quantidade de material de uma dada classe granulométrica, capaz de ser transportada pelo canal por unidade de tempo (STEVAUX e LATRUBESSE, 2017, p.140; BLOOM, 2004, p.215).

Entre as várias formas originadas pela sedimentação fluvial, pode-se citar a planície de inundação. A planície de inundação constitui a forma mais comum de sedimentação fluvial, encontrada em drenagens de todas as grandezas. No período de vazante ou águas baixas, a deposição da carga detrítica restringe-se a parcelas do canal fluvial. Entretanto, no período de cheia, com a elevação da cota fluviométrica ocasionando o transbordamento do rio para o leito maior, a deposição de carga detrítica abrange áreas baixas adjacentes ao rio (CHRISTOFOLETTI, 1980, p.76).

De acordo com Suguio (2003, p.233), as pesquisas relacionadas a modernos depósitos aluviais indicam que eles podem ser classificados em numerosas subfácies, cada uma depositada em um subambiente específico. Do ponto de vista geomorfológico e sob uma perspectiva didática, os depósitos fluviais podem ser subdivididos em três grupos: a) depósitos de canal; b) depósitos marginais; c) depósitos de planície de inundação. 
Entretanto, defende-se que essa separação é considerada equivocada, uma vez que os depósitos de canal e a planície de inundação, são formados pelo mesmo processo. Além disso, a existência de planície de inundação não depende da existência de diques marginais, ou seja, não é preciso que a água do rio rompa um dique natural para que os sedimentos aluviais sejam depositados, em áreas baixas adjacentes ao rio - planície de inundação.

A importância do mapeamento geomorfológico é atestada pelo fato deste produto ser aplicado a estudos de caráter multidisciplinar e não somente a estudos, cujos objetivos estão pautados apenas na classificação das formas do relevo. Desse modo, o mapeamento geomorfológico, hoje, reveste-se de um caráter mais prático, o qual procura relacionar aspectos da natureza física dos fenômenos, com aspectos da natureza socioeconômica destes. Acerca de algumas áreas em que o mapeamento geomorfológico é utilizado podem-se citar: a) projetos de gerenciamento ambiental, b) estudos de impacto ambiental e relatórios de impacto ambiental - EIA/RIMA e c) trabalhos de geotecnia. Dentre alguns objetivos, esses mapeamentos procuram: a) elucidar problemas erosivos e deposicionais em áreas de grande extensão, b) mediante a correlação com outros mapas temáticos, elaborar cenários ambientais, tais como: áreas de instabilidade de taludes e áreas de risco de movimento de massa ou de inundação e c) fornecer subsídios à instalação de obras viárias e à localização de rejeitos sépticos, entre outros (ARGENTO, 2005, p.366).

Com relação às inundações, na cidade de Jataizinho, observa-se que:

Na cidade de Jataizinho, existem duas situações no que concerne à ocorrência de inundação. A primeira diz respeito ao transbordamento natural do rio Tibagi para o leito maior, ocupado de forma irregular, principalmente por chácaras, nas quais residem, em grande maioria, famílias de classe média. A segunda ocorre dentro da área urbana, sendo a origem do fenômeno o remanso que o ribeirão Jataizinho, tributário do rio Tibagi, sofre em decorrência do aumento do nível deste (SOUSA, 2012, p.146).

O autor acrescenta, ainda, que:

É na segunda situação em que os danos sociais e econômicos são mais contundentes, ocasionando perdas materiais para o município e para as famílias de bairros pobres como: o bairro Frederico Lukarewisk e Vila Bernardes. O último é considerado o ponto mais crítico, com ocorrência inclusive de óbitos. Conforme informações concedidas por funcionários da prefeitura de Jataizinho, o prejuízo causado à cidade em janeiro de 2010, em decorrência de inundações, superou o montante de um milhão de reais (SOUSA, 2012, p.146).

\section{Localização e Caracterização Geológica e Geomorfológica da Área de Estudo.}

A área de estudo está localizada, no curso inferior do Rio Tibagi, considerado o principal tributário da margem esquerda do Rio Paranapanema, com aproximadamente $550 \mathrm{~km}$ de extensão, inserido em uma bacia hidrográfica com $24.712 \mathrm{Km}^{2}$ de área de drenagem, ambos constituintes da bacia hidrográfica do Rio Paraná (MAACK, 1981, p.329; FRANÇA, 2002, p.47).

A unidade morfoestrutural a qual se assenta a área de estudo é a Bacia Sedimentar do Paraná; enquanto a formação geológica que aflora em superfície é a Formação Serra Geral - JKsg pertencente ao Grupo São Bento. Esta formação é constituída por rochas magmáticas extrusivas, basicamente basaltos toleíticos. Originadas na Era Mesozoica, período Neojurássico, a datação

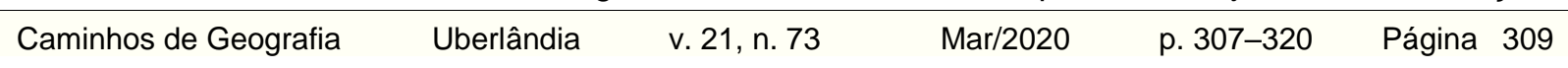


das rochas é de aproximadamente 140 m.a. Estudos revelaram que as espessuras das rochas podem atingir entre $450 \mathrm{~m}$ e $600 \mathrm{~m}$; entretanto, perfurações da Petrobrás, no Estado do Paraná, revelaram espessuras de até 1199 m (PETRI; FÚLFARO, 1983, p.235; DNPM, 1984, p.347; MAACK, 1981, p.420; MINEROPAR, 2001, p.15).

O Rio Tibagi abrange o Primeiro, o Segundo e o Terceiro Planalto Paranaense. A unidade morfoescultural, na qual se situa a cidade de Jataizinho, é o Planalto de Londrina, genericamente inserido no Terceiro Planalto Paranaense. De acordo com MINEROPAR (2006, p.20), a classe de declividade predominante no Planalto de Londrina é inferior a 12\%; enquanto o grau de entalhamento do relevo denota dissecação média.

A direção preferencial de fluxo do Rio Tibagi, segundo a análise de mapas de hidrografia, dá-se no sentido SE-NW; enquanto o padrão de drenagem evidenciado, conforme a classificação de Christofoletti (1980, p.104), é do tipo paralelo, decorrente entre outros fatores, dos controles estruturais existentes. A localização da área de estudo pode ser evidenciada na Figura 1.

Figura 1 - Localização da área de estudo.

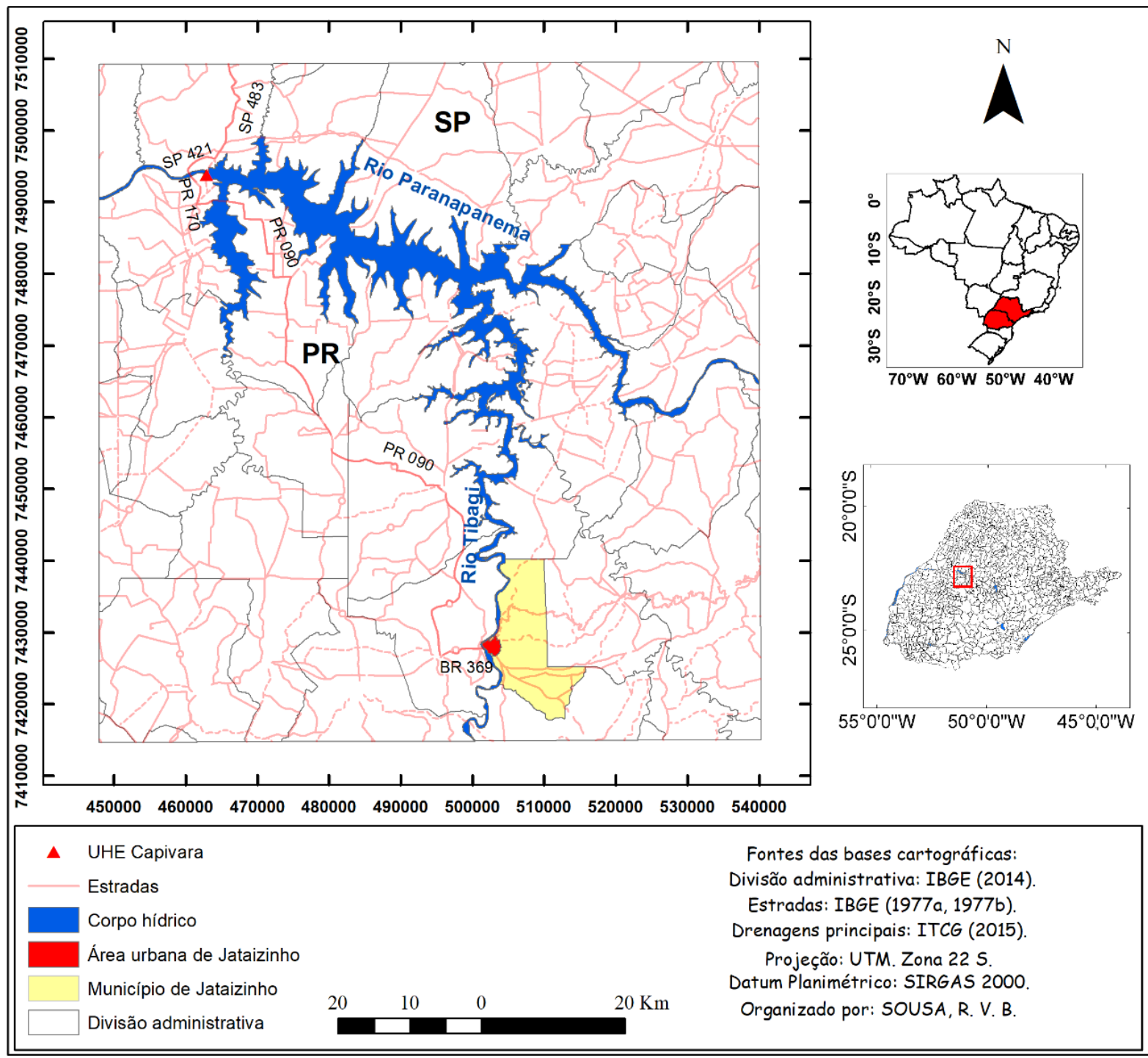

Org.: SOUSA, R. V. B. 

Julio Kiyoshi Hasegawa

\section{MATERIAIS E MÉTODOS}

O mapeamento geomorfológico foi realizado por meio de estereoscopia digital. O modelo estereoscópico foi construído com base em aerofotos da cidade de Jataizinho da década de 1970, na escala de 1:25000, utilizando-se como ferramenta o software Prestitui.exe, elaborado por Hasegawa (2010).

Com essa finalidade, utilizaram-se aerofotos do Instituto Brasileiro do Café - IBC (1970), especificamente as aerofotos 10795, 10796 e 10797, referentes à faixa 98 A, quadrícula SF.22 -ZC-I. Destaca-se que as aerofotos foram obtidas no Centro de Documentação e Pesquisa Histórica - CDPH, da Universidade Estadual de Londrina - UEL.

Para georreferenciar o par estereoscópico no software Prestitui.exe, utilizou-se um conjunto de coordenadas geodésicas coletado através de técnicas GNSS, especificamente, por meio da técnica relativa estática rápida pós-processada, apresentada em Monico (2008, p.339). A fim de aumentar a produtividade em campo, o tempo de coleta das coordenadas geodésicas in situ, foi de 10 minutos. Os dados foram pós-processados através do software GNSS Solutions. O datum planimétrico utilizado foi o SIRGAS 2000, de modo que a altitude elipsoidal também foi obtida com base neste datum. A projeção adotada foi a Universal Transversa de Mercator - UTM. A altitude geométrica elipsoidal foi convertida para altitude ortométrica - em relação ao geóide ou ao nível médio dos mares - através de um modelo de ondulação geoidal para o território brasileiro. Para isso, fez-se o uso do software MAPGEO 2010, disponível em IBGE (2015).

Destaca-se que outros dados foram utilizados para os devidos ajustes do modelo estereoscópico, tais quais: marcas fiduciais das aerofotos, escala das aerofotos, altitude média do terreno das aerofotos, altura de voo na tomada das aerofotos, distância focal calibrada e tipo de câmera utilizada para a obtenção das aerofotos.

Com relação à operacionalidade do software Prestitui.exe, este possui duas formas de visualizar a estereoscopia das aerofotos: a) modo binocular, o qual necessita de um par de espelhos estereoscópicos acoplado ao computador - assemelhando-se, portanto, à estereoscopia tradicional analógica - e b) modo anaglifo, o qual substitui os pares de espelhos estereoscópicos por óculos tridimensionais. O software também permite a visualização no modo monocular, sem espelhos estereoscópicos ou óculos 3D. Nesse modo, entretanto, o pesquisador não tem a visão estereoscópica, fato que pode não conferir bons resultados na fotointerpretação.

O software possibilita construir dados vetoriais, tais quais, pontos e sequência de segmentos de retas que descreve um objeto, cujas localizações do ponto final e do ponto inicial deste se diferem - feição aberta ou linha - e sequência de segmentos de retas que descreve um objeto, cujas localizações do ponto final e do ponto inicial deste se coincidem - feição fechada ou polígono. Assim, se a intenção é representar a altitude de um local no relevo, usa-se a feição aberta. Caso o interesse seja representar formas do relevo - como planície fluvial, terraço, colina, entre outras usa-se a feição fechada.

O software permite converter os arquivos salvos em bloco de texto para a extensão DXF, viabilizando a manipulação em softwares de geoprocessamento.

\begin{tabular}{|c|}
\hline \\
\hline Caminhos de Geografia \\
\hline
\end{tabular}


Conforme Tricart (1965, p.187), um mapa geomorfológico deve ser composto por quatro níveis de detalhamento: a) dados morfométricos, b) informações morfográficas, c) dados morfogenéticos e d) cronologia. No cômputo geral, os mapas geomorfológicos devem conter informações sobre os tipos de formas de relevo, gênese e idade. Nesse sentido, as bases teóricas utilizadas para a classificação das formas de relevo mapeadas foram Ross (1992), Ross e Moroz (1997) e Brasil (2009). Devido ao objetivo da pesquisa, isto é, executar mapeamento geomorfológico destinado a auxiliar o entendimento das causas responsáveis pelas inundações, julgou-se conveniente realizar o mapeamento geomorfológico até o 4ํ táxon de Ross (1992).

Durante a etapa de identificação e delimitação das formas de relevo, procurou-se identificar as planícies fluviais e os terraços, com base nas rupturas de declive, caracterizadas pelas menores variações bruscas nas aerofotos. Segundo Soares e Fiori (1978, p.42), a disposição regular das rupturas de declive, no espaço, constitui estrutura do relevo classificadas como: quebras negativas ou quebras positivas, ou, ainda, lineações ou alinhamentos do relevo. As duas primeiras, estão contidas em um plano ou superfície regular que define a forma de estruturação. Especificamente com relação à quebra negativa, esta pode ser definida como forma rebaixada no relevo, formada pela disposição estruturada das rupturas de declive com a concavidade voltada para cima.

Após a delimitação das feições de interesse, estas foram sobrepostas a uma imagem orbital ortorretificada do satélite Rapideye, com resolução espacial de $5 \mathrm{~m}$ e com data de imageamento em setembro de 2012, obtida gratuitamente junto a Brasil (2014), especificamente, junto ao Geo Catálogo, um banco de imagens orbitais gerenciado pelo Ministério do Meio Ambiente - MMA. O objetivo da sobreposição foi verificar se áreas susceptíveis à inundação, atualmente são ocupadas por moradores da cidade de Jataizinho.

As classes de declividade das formas de relevo foram obtidas com base em técnicas de geoprocessamento e classificadas de acordo com a Empresa Brasileira de Pesquisa Agropecuária - EMBRAPA (1979). Devido à inexistência de cartas topográficas de órgãos oficiais, em escala compatível às aerofotos e à resolução espacial das imagens orbitais utilizadas, foram empregados dados topométricos do projeto TOPODATA, disponibilizado por INPE (2011), interpolando-se os dados do Modelo Digital de Elevação - MDE -, para obtenção de curvas de nível com equidistância de $10 \mathrm{~m}$. Vale salientar que as curvas de nível das cartas topográficas do IBGE, em escala 1:50.000 e equidistância de $20 \mathrm{~m}$, apresentaram detalhamento insuficiente da declividade do terreno, nas adjacências dos canais fluviais, o que demandou a utilização de outros produtos. A sobreposição dos layers, a obtenção dos dados de declividade e as etapas rotineiras de préprocessamento e pós-processamento foram realizadas através de técnicas de geoprocessamento.

\section{RESULTADOS E DISCUSSÃO}

O mapa geomorfológico do sítio urbano de Jataizinho e a respectiva legenda expandida deste podem ser observados na Figura 2; enquanto o mapa de declividade do terreno da cidade de Jataizinho pode ser observado na Figura 3. 
Figura 2 - Mapa geomorfológico do sítio urbano de Jataizinho.

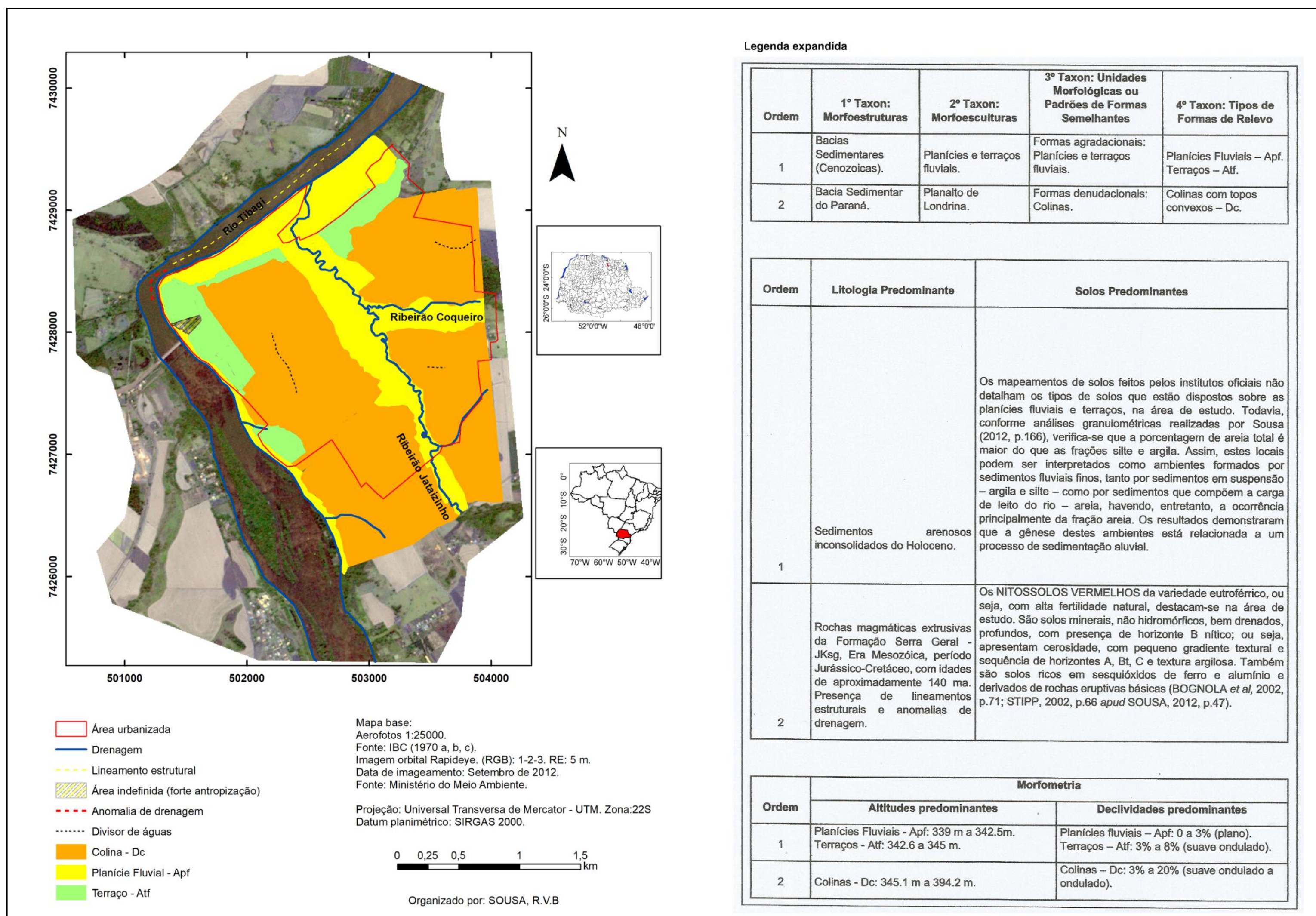

Org.: SOUSA, R. V. B. 
Figura 3 - Mapa clinográfico do sítio urbano de Jataizinho.

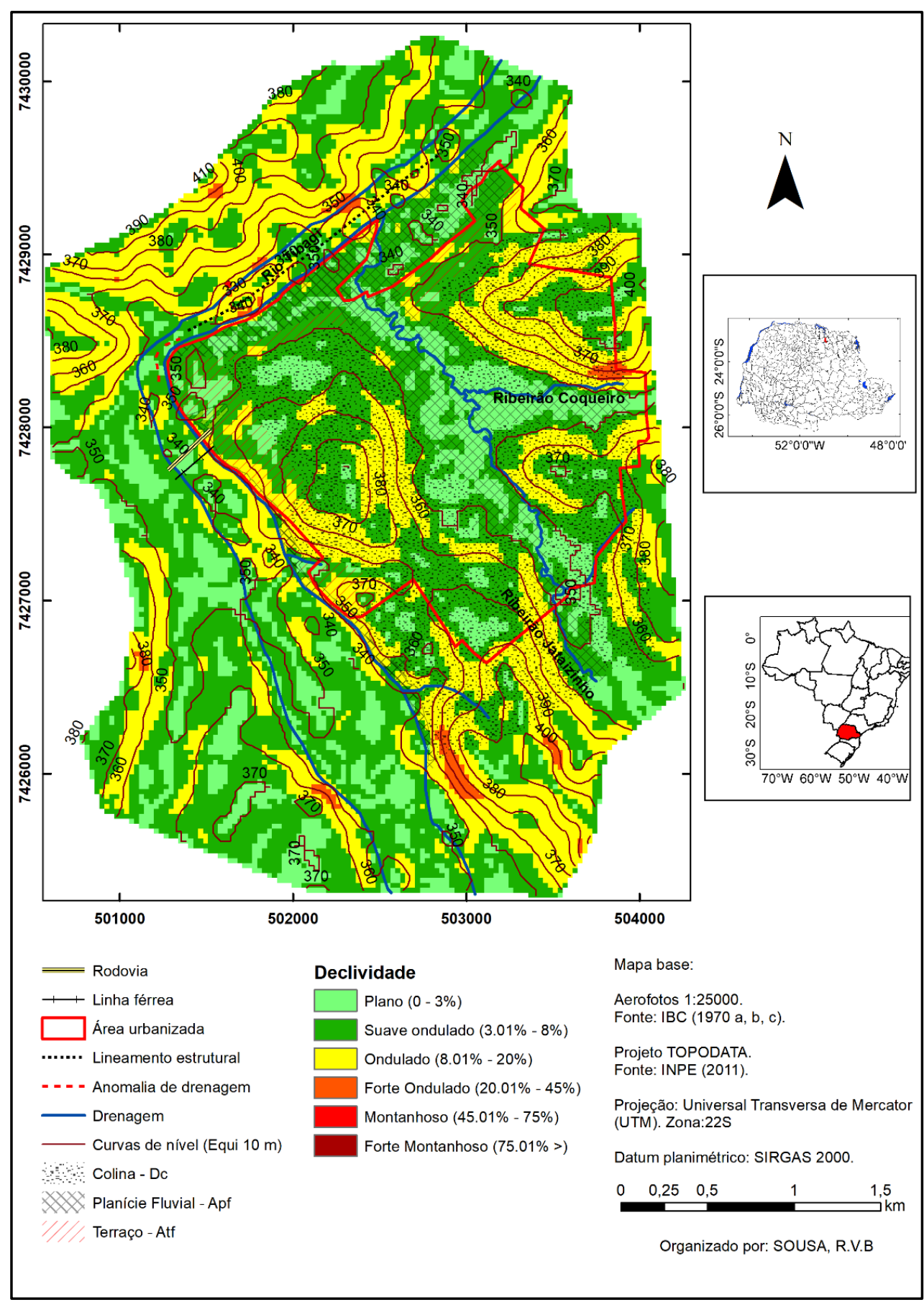

Org.: SOUSA, R. V. B.

Verifica-se que as principais formas agradacionais mapeadas são planícies fluviais - Apf - e terraços - Atf; enquanto as principais formas denudacionais mapeadas são colinas com topos convexos - Dc,

A morfoestrutura das formas denudacionais é a Bacia Sedimentar do Paraná; enquanto a morfoestrutura das formas deposicionais diz respeito a depósitos sedimentares atuais do Cenozoico.

Acerca da morfoescultura, as formas denudacionais correspondem ao Planalto de Londrina; sendo que as formas agradacionais se referem a planícies e terraços fluviais.

Quanto à morfometria das formas de relevo mapeadas, os resultados apontam que as planícies fluviais - Apf - denotam altitudes entre $339 \mathrm{~m}$ e $342,5 \mathrm{~m}$ e declividades entre 0 e $3 \%$; os terraços -

Caminhos de Geografia Uberlândia $\quad$ v. 21, n. $73 \quad$ Mar/2020 $\quad$ p. 307-320 Página 314


Atf - apresentam altitudes entre $342,6 \mathrm{~m}$ e $345 \mathrm{~m}$ e declividades entre $3 \%$ e $8 \%$; enquanto as colinas - Dc possuem altitudes entre 345,1 m e 394,2 m e declividades entre $3 \%$ e $20 \%$.

A litologia predominante das planícies fluviais e dos terraços diz respeito a sedimentos arenosos inconsolidados do Holoceno; enquanto a litologia predominante das colinas diz respeito a rochas magmáticas extrusivas da Formação Serra Geral - JKsg. Destaca-se que, lineamentos estruturais e anomalias de drenagem são observados na área mapeada. Com base em Soares e Fiori (1978, p.40), a anomalia de drenagem identificada é do tipo cotovelo.

Os solos predominantes nas áreas agradacionais, conforme Sousa (2012, p.166), denotam maior porcentagem de areia total em detrimento das frações silte e argila. Assim, estes locais podem ser interpretados como ambientes formados por sedimentos fluviais finos, tanto por sedimentos em suspensão - argila e silte - como por sedimentos que compõem a carga de leito do rio - areia, havendo, entretanto, a ocorrência principalmente da fração areia. Os resultados demonstraram que a gênese destes ambientes está relacionada a processos de sedimentação aluvial.

Quanto aos solos predominantes nas áreas denudacionais, observam-se os NITOSSOLOS VERMELHOS da variedade eutroférrico, ou seja, com alta fertilidade natural (BOGNOLA et. al, 2002, p.71 e STIPP, 2002, p.66 apud SOUSA, 2012, p.47).

A sobreposição das formas de relevo sobre a imagem orbital deixa evidente que as planícies fluviais - Apf -, adjacentes ao Rio Tibagi, Ribeirão Jataizinho e Ribeirão Coqueiro, são ocupadas por habitantes de Jataizinho, da mesma forma como alguns limites entre planície fluvial e terraço igualmente são ocupadas. Nesse sentido, a ocupação das planícies fluviais, com altitude entre $339 \mathrm{~m}$ e $342.5 \mathrm{~m}$ e declividades entre $0 \%$ e $3 \%$, deve ser considerada um fator de grande relevância para os impactos socioeconômicos decorrentes das inundações, na cidade de Jataizinho.

Destaca-se que, em conjunto com as demais variáveis hidroclimáticas e antropogênicas responsáveis pelas inundações, na cidade de Jataizinho, apontadas por Sousa (2017, p.346), a anomalia de drenagem do Rio Tibagi identificada no mapa geomorfológico, especificamente, o cotovelo, talvez tenha a capacidade de contribuir para a ocorrência de inundações mais bruscas. Assim, com base nessa hipótese, numa situação com alta taxa de precipitação sobre a Bacia Hidrográfica do Tibagi, suficiente para provocar uma onda de cheia, a anomalia de drenagem teria a capacidade de estrangular a vazão de montante e aumentar a velocidade de fluxo a jusante, no trecho do Rio Tibagi controlado pelo lineamento estrutural, onde se localiza a principal área da cidade de Jataizinho afetada pelo transbordamento do Rio Tibagi e onde se localiza a seção transversal da estação fluviométrica Jataizinho - 64507000.

A área mapeada para cada tipo de relevo pode ser observada na (Tabela 1). Os resultados apontam que aproximadamente $67 \%$ da área mapeada são colinas - Dc -, $22 \%$ são planícies fluviais - Apf -e $11 \%$ são terraços - Atf -, de modo que as áreas deposicionais correspondem a $33 \%$ da área de estudo.

Tabela 1 - Área das formas de relevo mapeadas.

\begin{tabular}{l|c|c|c|c}
\hline & $\begin{array}{c}\text { Colina - } \\
\text { Dc }\end{array}$ & $\begin{array}{c}\text { Terraço - } \\
\text { Atf }\end{array}$ & $\begin{array}{c}\text { Planície Fluvial - } \\
\text { Apf }\end{array}$ & Área indefinida \\
\hline Área $\left(\mathrm{km}^{2}\right)$ & 3,91 & 0,61 & 1,31 & 0,02 \\
\hline $\begin{array}{l}\text { Porcentagem } \\
(\%)\end{array}$ & 66,91 & 10,38 & 22,41 & 0,30 \\
\hline \multicolumn{4}{r|}{ Org.: SOUSA, R. V. B. }
\end{tabular}

Imagens de controle de campo para aferição das formas de relevo mapeadas, com ênfase para as áreas deposicionais, podem ser observadas na Figura 4. Correlacionando essas imagens com a sobreposição do mapeamento geomorfológico e da imagem orbital, aplicando-se um efeito de transparência nos arquivos vetoriais, verifica-se que atualmente parte considerável das áreas de planície fluvial são antropizadas, inclusive com a existência de moradias.

Além da ocupação das planícies fluviais, em algumas situações as mesmas foram suprimidas por meio de aterramento em propriedades particulares, a fim de evitar prejuízos advindos das inundações, fato observado durante os trabalhos de campo. Outra constatação que explicita profunda modificação do relevo e das drenagens da área urbana de Jataizinho, reside no fato de não se observar mais em campo, algumas drenagens presentes na carta topográfica da área em escala 1:50.000, o que leva a crer que estas drenagens foram canalizadas em galerias, para viabilizar a ocupação de alguns terrenos.

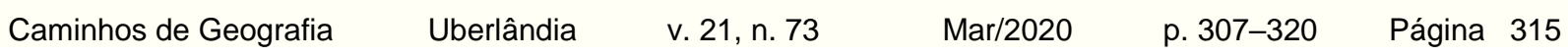


Figura 4 - Imagens de controle de campo para aferição das formas de relevo.

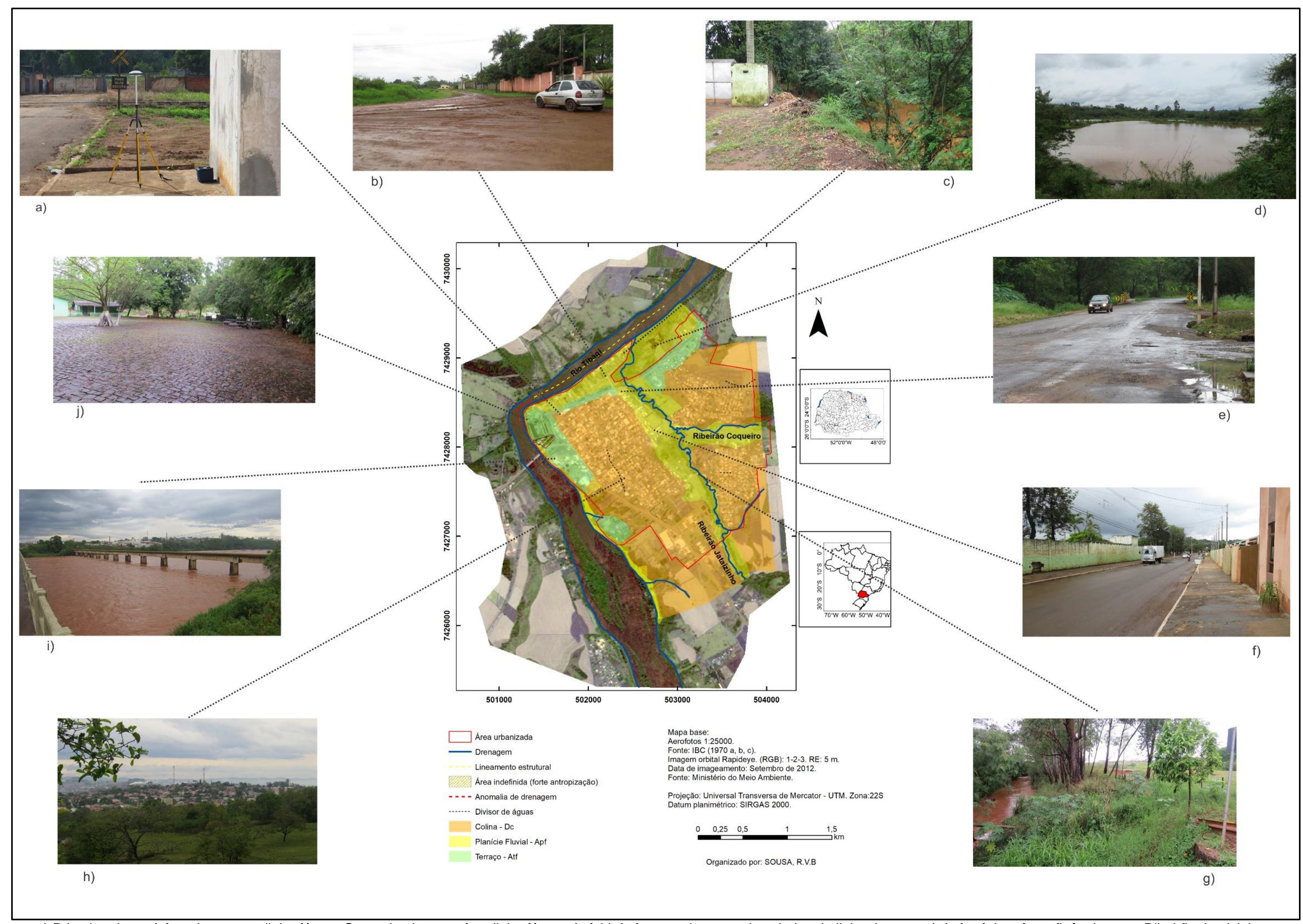

a) Primeiro plano: Atf, onde passa a linha férrea. Segundo plano, após a linha férrea: Apf; b) Apf em quebra negativa abaixo da linha do trem; c) Apf próximo à confluência entre Ribeirão Jataizinho e Rio Tibagi; d) antigas cavas para extração de argila localizada em Apf; e) Apf do Ribeirão Jataizinho (ponte sobre este ao fundo), próximo à Atf do Rio Tibagi, ao norte. Av. Presidente Getúlio Vargas com Rua Curitiba, próximo à Associação dos Pescadores; f) Apf: Vila Frederico Lucarewisk, um dos locais mais pobres e mais atingidos por inundações, na cidade de Jataizinho; Apf do Ribeirão Jataizinho; h) Dc em segundo plano; i) Em primeiro plano,
servidores municipais de Jataizinho. Org.: SOUSA, R. V. B. 
Além de identificar as formas de relevo, o uso da estereoscopia digital permitiu calcular o nível de margens plenas do Rio Tibagi no sítio urbano de Jataizinho, embora esta etapa não tenha sido simples. Isso porque, ora algumas áreas próximas ao Rio Tibagi se mostravam bastante alteradas pela ação humana, ora existia vegetação arbórea nas margens, fato que não permitia identificar a altitude do terreno, mas, sim, do dossel da vegetação. Mesmo assim, foi possível identificar a altitude das margens plenas em um ponto próximo à foz do Ribeirão Jataizinho, apresentando as seguintes coordenadas geodésicas: $X=502416,6029 \mathrm{~m}, \mathrm{Y}=7429136,3040 \mathrm{~m}$ e $Z=339,346 \mathrm{~m}$.

Destaca-se, também, que, o uso de técnicas GNSS permitiu calcular a cota zero do primeiro lance de régua da estação fluviométrica Jataizinho - 64507000, igual a 334,02 m. Nesse sentido, o cálculo das altitudes ortométricas do nível de margens plenas e da cota zero do primeiro lance de régua, mostram-se como dados de fundamental importância para pesquisas hidrológicas na área de estudo, principalmente, pesquisas relacionadas a inundações.

Procurou-se relacionar o nível de margens plenas identificado por estereoscopia $\left(\mathrm{N}_{\mathrm{mp} 1}\right), 339,346 \mathrm{~m}$, com um segundo nível de margens plenas $\left(\mathrm{N}_{\mathrm{mp} 2}\right)$, calculado com base nos valores da cota zero do primeiro lance da régua da estação fluviométrica Jataizinho - 64507000 -, e da altura da cota de transbordamento registrada no histórico da estação fluviométrica Jataizinho. O objetivo foi verificar se haveria diferença significativa nos valores das altitudes das margens plenas.

Assim, de posse dos valores da altitude da referência de nível 1 da estação fluviométrica Jataizinho $\mathrm{RN} 1$-, e da altura da cota de transbordamento, o $\mathrm{N}_{\mathrm{mp} 2}$ foi calculado por meio da Equação 1, da Equação 2 e da Equação 3.

$\mathrm{N}_{\mathrm{mp} 2}=\left[\left(\mathrm{RN} 1_{\text {gnss }}-\mathrm{RN} 1\right)+\mathrm{C}_{\mathrm{t}}\right]$

Sabendo-se que:

$\left(\mathrm{RN} 1_{\text {gnss }}-\mathrm{RN} 1\right)=\mathrm{C}_{0}$ gnss

Tem-se que:

$\mathrm{N}_{\mathrm{mp2}}=\mathrm{C}_{0}$ gnss $+\mathrm{C}_{\mathrm{t}}$

Sendo:

$\mathrm{N}_{\mathrm{mp} 2}=$ Nível de margens plenas calculado com base nos valores de cota zero da régua e da altura da cota de transbordamento registrada no histórico da estação fluviométrica Jataizinho -64507000 .

$\mathrm{RN1} 1_{\text {gnss }}=$ Altitude ortométrica da referência de nível 1, obtida por técnicas GNSS (343,590 m).

RN1 = Altura da referência de nível 1 - marco fixado em campo $(9,570 \mathrm{~m})$.

$\mathrm{C}_{0}$ gnss $=$ Cota zero obtida por técnicas GNSS (334,02 m).

$\mathrm{Ct}=$ Cota de transbordamento registrada no histórico da estação fluviométrica $(5,40 \mathrm{~m})$.

Sendo o resultado de $\mathrm{N}_{\mathrm{mp} 2}$ igual a $339,42 \mathrm{~m}$ e do $\mathrm{N}_{\mathrm{mp} 1}$ equivalente a $339,346 \mathrm{~m}$, concluiu-se que a diferença entre os dois níveis de margens plenas é de $7,4 \mathrm{~cm}$, mostrando-se os dois resultados muito próximos. O nível de margens plenas adotado foi o $\mathrm{N}_{\mathrm{mp} 1}, 339,346 \mathrm{~m}$, ou seja, aquele obtido com base nas técnicas aerofotogrametria digital.

\section{CONSIDERAÇÕES FINAIS}

O mapeamento geomorfológico apresentado nesse artigo apontou que muitas planícies fluviais - Apf -, atualmente são ocupadas por habitantes da cidade de Jataizinho. Desse modo, independente das causas responsáveis pelo transbordamento dos canais fluviais, essa constatação tem um peso significativo no que concerne aos impactos socioeconômicos decorrentes das inundações, na cidade de Jataizinho, ressaltando que a cidade é afetada recorrentemente por esse tipo de problema.

A anomalia de drenagem do Rio Tibagi identificada no mapa geomorfológico, especificamente, o cotovelo, talvez tenha a capacidade de contribuir para a ocorrência de inundações mais bruscas, estrangulando a vazão de montante e, na sequência, aumentando a velocidade de fluxo do rio a jusante, no trecho do Rio Tibagi controlado pelo lineamento estrutural, onde se localiza a principal área da cidade de Jataizinho afetada pelo transbordamento do Rio Tibagi.

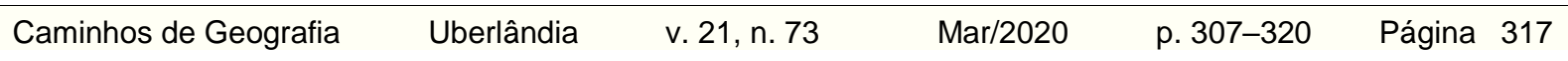


Para pesquisas hidrológicas e geomorfológicas futuras, na área de estudo, principalmente pesquisas relacionadas a inundações, podem ser utilizadas como referência de nível de transbordamento do Rio Tibagi, as altitudes ortométricas: a) do nível de margens plenas do Rio Tibagi, a saber: 339,346 m, equivalente a $532,6 \mathrm{~cm}$ na régua linimétrica, e b) da cota zero do primeiro lance de régua da estação fluviométrica Jataizinho - 64507000, qual seja, 334,020 m, na medida em que estes dados foram obtidos por técnicas de aerofotogrametria digital e técnicas GNSS.

O software Prestitui.exe, mostrou-se satisfatório para a delimitação das formas de relevo, pois além da praticidade possibilitou fácil integração dos produtos gerados a outros softwares de geoprocessamento.

O mapeamento geomorfológico executado nesta pesquisa, poderá ser utilizado como ferramenta de apoio ao planejamento territorial e ambiental da cidade de Jataizinho, em conjunto com outros produtos cartográficos e planos de gestão territorial já desenvolvidos pela prefeitura desta cidade. Recomenda-se a inserção do mapeamento geomorfológico executado no Plano Diretor do município.

\section{AGRADECIMENTOS}

À Coordenação de Aperfeiçoamento de Pessoal de Nível Superior - CAPES -, pelo aporte financeiro para o desenvolvimento desta pesquisa, parte do projeto de Doutorado em Geografia pela UNESP, Campus de Presidente Prudente.

\section{REFERÊNCIAS}

ARGENTO, M. S. F. Mapeamento geomorfológico. In: GUERRA, Antonio J. T; CUNHA, Sandra B. da. Geomorfologia: Uma atualização de bases e conceitos. 6ª ed. Rio de Janeiro: Bertrand Brasil, 2005, p.366-367.

BLOOM, A. L. Geomorphology: A systematic analysis of late cenozoic landforms. USA: Waveland Press, 2004, p.215.

BRASIL. Ministério do Meio Ambiente - MMA; Agência Nacional de Águas - ANA. Sistema Nacional de Informações sobre Recursos Hídricos. Mapa de vulnerabilidade a inundações - Brasil. Brasília: ANA, 2015a. Disponível em: < http://www2.snirh.gov.br/home/webmap/viewer.html?webmap=cf201bd9b2c540fa951b0619006eb2af> . Acesso em: 10 jul. 2015. ;

Atlas de vulnerabilidade a inundações - Região Sul. Brasília: ANA, 2015b. Disponível em: < http://metadados.ana.gov.br/geonetwork/srv/pt/main.home>. Acesso em: 10 jul. 2015.

em: $14 / 07 / 2014$

Geo Catálogo. 2014a. Disponível em:< http://geocatalogo.ibama.gov.br/>. Acesso

Secretaria Nacional de Saneamento Ambiental. Gestão do território e manejo integrado das águas urbanas. Brasília: Ministério das Cidades, 2005.

CHRISTOFOLETTI, A. Geomorfologia. 2. ed. São Paulo: Edgard Blücher, 1980, p.1-105.

DNPM - Departamento Nacional de Produção Mineral - DNPM. Geologia do Brasil. Brasília: 1984, p.341-347.

EMBRAPA. - Empresa Brasileira de Pesquisa Agropecuária. Serviço Nacional de Levantamento e Conservação de Solos. Súmula da 10 Reunião Técnica de Levantamento de Solos. Rio de Janeiro: 1979, 83pp.

FRANÇA, $V$ de. $O$ rio Tibagi no contexto hidrogeográfico paranaense. In: MEDRI, Moacyr E., et al. (Ed). A Bacia do Rio Tibagi. Londrina: EDUEL, 2002, p.45-61. 
HASEGAWA, J. K. Simulador digital do restituidor analógico: Orientação e restituição fotogramétrica digital baseada em técnicas analógicas. Presidente Prudente: FCT - UNESP, 2010, $60 \mathrm{p}$.

IBC - Instituto Brasileiro do Café. Projeto PR. Aerofotos 10795, 10796 e 10797.. Faixa 98 A. Quadrícula: SF.22 - Z - C - I. 1970.

IBGE - Instituto Brasileiro de Geografia e Estatística. Bases e referenciais: Bases cartográficas; malhas digitais. Tipo de dado (vetorial). 2014. Disponível em: <https://mapas.ibge.gov.br/bases-ereferenciais/bases-cartograficas/malhas-digitais.html>. Acesso em: 30.nov.2014.

CORNÉLIO PROCÓPIO. FOLHA: SF.22-Z-C. MIR 497. Tipo do dado (vetorial). 1977a. Disponível em: < http://www.itcg.pr.gov.br/modules/conteudo/conteudo.php?conteudo=103>. Acesso em: 30.nov.2014.

Geodésia - Modelo de ondulação geoidal: MAPGEO 2010, versão 1.0. 2015. Disponível $\mathrm{em}:$ < http://www.ibge.gov.br/home/geociencias/geodesia/modelo_geoidal.shtm>. Acesso em: 15/05/2015.

LONDRINA. FOLHA: SF.22-Y-D. MIR 496. Tipo do dado (vetorial). 1977b. Disponível em: < http://www.itcg.pr.gov.br/modules/conteudo/conteudo.php?conteudo=103>. Acesso em: 30.nov.2014.

Manuais técnicos em geociências: Manual técnico de geomorfologia. 2. ed, n.5. Rio de Janeiro: IBGE, Coordenação de Recursos Naturais e Estudos Ambientais, 2009.

INPE - Instituto Nacional de Pesquisas Espaciais -. TOPODATA: Banco de dados geomorfométricos do Brasil. INPE, 2011. Disponível em:< http://www.dsr.inpe.br/topodata/index.php>. Acesso em: 10 mai. 2015.

MAACK, R. Geografia Física do Estado do Paraná. 2. ed. Rio de Janeiro: J. Olympio; Curitiba: Secretaria da Cultura e do Esporte do Governo do Estado do Paraná, 1981, p.329-420.

MINEROPAR - Minerais do Paraná S.A. Atlas Geológico do Estado do Paraná. Curitiba: Governo do Estado do Paraná, 2001, p.15.

Atlas Geomorfológico do Estado do Paraná: Escala Base 1:250.000. Modelos Reduzidos 1:500.000. Curitiba: Universidade Federal do Paraná, 2006, p.20-31.

MONICO, J. F. G. Posicionamento pelo GNSS: Descrição, fundamentos e aplicações. $2^{\underline{a}}$ ed. São Paulo: Editora UNESP, 2008, 476p.

PETRI, S; FÚlFARO, J. V. Geologia do Brasil. São Paulo: Universidade de São Paulo, v. 9, 1983, p.235.

ROSS, J. L. S. O registro cartográfico dos fatos geomorfológicos e a questão da taxonomia do relevo. Revista do Departamento de Geografia. v.6, p.17-29, 1992. Disponível em: < http://www.revistas.usp.br/rdg/article/view/47108>. Acesso em: $05 . \quad$ mar. 2014. https://doi.org/10.7154/RDG.1992.0006.0002

; MOROZ, I. C. Mapa Geomorfológico do Estado de São Paulo: Escala 1:500.000. São Paulo: FFLCH-USP, 1997.

SOARES, P. C; FIORI, Alberto P. Lógica e sistemática na análise e interpretação de fotografias aéreas em geologia. Bol. Geogr. Rio de Janeiro, 36, p.35-59, jul./dez, 1978, p.40-43.

SOUSA, R. V. B. Estudo sobre as inundações no curso inferior do rio Tibagi - PR. 2012. $191 \mathrm{f}$. Dissertação (Mestrado em Geografia) - Universidade Estadual de Londrina, Londrina, 2012.

Ocorrências de inundações no baixo curso do Rio Tibagi, município de Jataizinho PR: Variáveis determinantes, 2017, 449 pp. Tese (Doutorado em Geografia). Universidade Estadual 
Paulista "Júlio de Mesquita Filho", Faculdade de Ciências e Tecnologia - UNESP, Campus de Presidente Prudente.

STEVAUX, J. C; LATRUBESSE, E. M. Geomorfologia fluvial. São Paulo: Oficina de textos, 2017, p.140-241.

SUGUIO, K. Geologia sedimentar. São Paulo: Edgar Blücher, 2003, p.220-291.

TRICART, J. Principes et méthodes de la geomorphologie. Paris: Masson et Cie. Editeurs, 1965, p.187-189. https://doi.org/10.1097/00010694-196510000-00015

Recebido em: 21/06/2019

Aceito para publicação em: 16/12/2019 